FORT COLLINS, Colo.-Federal funding agencies are gearing up to solicit and fund record levels of Small Business Innovation Research (SBIR) grants. Under Congressional mandate, the share of federal $R \& D$ money allocated to the SBIR program will more than double over the next two years.

"We expect to provide more than $\$ 1.5$ billion over the next five years in government funding for research in small, high technology firms," explains Roland Tibbetts, program manager for SBIR grants at the National Science Foundation (NSF) and a prime mover in getting the SBIR program enacted. "Biotechnology firms will certainly be included in this funding."

The biggest chunk of funding for biotechnology-related projects comes from the National Institutes of Health (NIH): $\$ 20.7$ million in SBIR grants this year and over $\$ 40$ million slated for 1985. NSF has allocated approximately $\$ 2$ million to biotech projects thus far. Phase-one projects are funded up to $\$ 40-50,000$ for a six month feasibility study. If the results of the phase-one project are positive, researchers can apply for phase-two funding to support development over one to two years. Phase-two funding levels vary from agency to agency: NSF has a $\$ 200,000$ limit, USDA funds up to $\$ 250,000$, while NIH provides as much as $\$ 500,000$. Only about 5 or 10 percent of the phaseone proposals receive funding, but funding ratios for phase-two grants have been very high at NIH $(85 / 125$ applications) and USDA (13/14 applications). Competition is stiffer at NSF.

While enthusiastic about the program, scientists from small biotech companies point out that it is not simply a gift. "It takes a lot of time to write a decent proposal," says Malcolm Finkelman of Genex Corp. (Gaithersburg, MD), “and $\$ 50,000$ will only support one junior-level person. I am not sure if it is worth it. The SBIR program would be more attractive if the funding level was high enough to ensure it would be adequate to cover the cost of high technology research."

Another drawback of SBIR grants is the hiatus-usually 6 to 12 months-between phase-one and phase-two funding. "As a small company, we are particularly disconcerted by the on-and-off nature of SBIR funding," explains Edward O. Lanphier, vice president for corporate development of Synergen (Boulder, $\mathrm{CO})$. "You submit a proposal and it takes a relatively long time until you get funded. You have a six month period of funding, then there is an interruption while you submit for phase two. The waiting and interruptions can create a very difficult situation for a small company."

In some cases, state governments are trying to help high tech firms solve the problem of tiding over projects. Last summer New York enacted legislation that provides funding of up to $\$ 50,000$ during the SBIR hiatus. "What we hope to do is to take phase-one winners and keep them on the development track until they receive phase-two funding under the SBIR program," says John Defigos, deputy executive director of the New York Foundation for Science and Technology (Albany, NY), which will administer the program. New York is the only state that has funded such a program so far, but several other states are considering similar legislation, Tibbetts reports. NIH also hopes to find a way to minimize between-phase disruption of funds.

Responding to the scientists' criticisms, Tibbetts admitted that "some facets of the program can be a handicap. But in developing the program we decided to try to fund as many projects as possible, which meant limiting the size of the awards. Of course, having both a large number of awards and a larger amount of money is attractive. But I think our program has worked out a realistic compromise." -Tazewell Wilson

\title{
SELF-DEFENSE FOR YEAST
}

HARROGATE, U.K.--Strains of Saccharomyces cerevisiae that produce toxins active against other yeasts and bacteria could curb contamination considerably during brewing and similar processes. That forecast was given by Roy Tubb, from the U.K. Brewing Research Foundation (Redhill, Surrey), during the Third Brewing Technology conference held here. Although brewers have always tried to select and maintain pedigree strains with desirable characteristics, Tubb said, gene transfer has still exerted only a modest influence on their craft. Along with developing yeasts producing their own amylolytic enzymes, and others able to metabolize lactose, he listed the manipulation of genes coding for toxins as one of the major targets for yeast genetics in the future.

Work at Redhill and elsewhere has shown that the double-stranded RNA determinants for production of (and immunity to) toxins called zymocins can be transferred from yeasts naturally carrying them into brewing strains. Because dsRNA exists in the cytoplasm rather than the nucleus, this is achievable by cytoduction- $-\mathrm{a}$ form of hybridization in which only cytoplasm comes from the donor. Often, however, the result is to generate a hybrid with impaired brewing characteristics, because "foreign" mito- chondrial DNA is introduced along with the dsRNA. As described in a forthcoming paper in Brewing Guardian, the recent breakthrough at Redhill has been to make an RNA copy of the relevant dsRNA, clone it into a vector, and thus introduce the zymocin gene alone into the recipient yeast.

Tubb predicts that zymocin-producing $S$. cerevisiae strains are likely to be made in future by transformation using recombinant DNA plasmids. Interest in the technique will, he feels, be confined initially to breweries using single strains of yeast and producing draft beers which are caskconditioned. "Real ale," whose yeast remains active in the barrel, is the obvious candidate. For the moment, however, the complicated task of introducing zymocin production and immunity simultaneously into all of several strains in one brewery would be inordinately difficult.

Genes coding for other antimicrobial toxins-particularly antibacterial agents-could be manipulated in the same way, Tubb and his colleagues believe. And now that the influence of mitochondrial DNA on brewing characteristics has been discovered, manipulating those properties independently of the yeast nucleus becomes a possible strategy for strain improvement. 